\title{
Uso de RT-PA alteplasa intraventricular en hemorragia intraventricular cerebral
}

Use of intraventricular rt-PA alteplase in cerebral intraventricular hemorrhage

MD Karla Garcés. ${ }^{1}$, MD María José Cuadrado. ${ }^{2}$, MD Juan Luzuriaga ${ }^{3}$ \& MD Galo Martínez ${ }^{4}$

Recibido: 10-10-2018 / Revisado: 17-11-2018 /Aceptado: 04-12-2018/ Publicado: 05-01-2019

\begin{abstract}
.
DOI: $\underline{\text { https://doi.org/10.33262/cienciadigital.v3i1.247 }}$

The presence of blood in the ventricular space produces a mass effect and hydrocephalus with a subsequent increase in intracranial pressure (ICP) and a decrease in cerebral perfusion pressure (CPP). In these cases the treatment consists of the placement of an external ventricular drain (DVE) that allows to regulate the excess of cerebrospinal fluid (CSF) and blood. The continuous presence of blood can imply obstruction of the DVE requiring frequent washing, being the use of fibrinolytics at the intraventricular level an adjuvant measure for this problem. The lysis of the clot within the ventricle depends on the conversion of the plasma protein plasminogen to plasmin, a proteolytic enzyme capable of digesting fibrin, fibrinogen and other proteins, the ventricular compromise does not depend on the fibrinolytic state of the systemic circulation, but on the activity in cerebrospinal fluid (CSF), often less effective and incomplete.

To present the experience obtained from the clinical case after the use of intraventricular alteplase in a patient with a diagnosis of arteriovenous malformation (AVM) complicated with cerebral intraventricular hemorrhage (HICCE) and hydrocephalus.
\end{abstract}

Keywords: MAV (Arteriovenous malformation), DVE (external ventricular shunt), (HIVCE) Cerebral intraventricular hemorrhage, ICP (intracranial pressure), PPC (cerebral perfusion pressure)

${ }^{1}$ Clínica Guayaquil, Guayaquil Ecuador, karlagarcesmd@ hotmail.com

${ }^{2}$ Clínica Kennedy, Guayaquil Ecuador, majitop_15@hotmail.com

${ }^{3}$ Clínica Guayaquil, Guayaquil Ecuador, jaluzu@hotmail.com

${ }^{4}$ Hospital Solca, Guayaquil Ecuador, galomartinezmd@hotmail.com 


\section{Resumen.}

La presencia de sangre en el espacio ventricular produce efecto de masa e hidrocefalia con posterior incremento de la presión intracraneal (PIC) y una disminución de la presión de perfusión cerebral (PPC). En estos casos el tratamiento consiste en la colocación de un drenaje ventricular externo (DVE) que permite regular el exceso de líquido cefalorraquídeo (LCR) y sangre. La presencia continua de sangre puede implicar obstrucción del DVE requiriéndose lavados frecuentes, siendo el uso de fibrinolíticos a nivel intraventricular una medida coadyuvante para este problema. La lisis del coágulo dentro del ventrículo depende de la conversión de la proteína plasmática plasminógeno a plasmina, una enzima proteolítica capaz de digerir fibrina, fibrinógeno y otras proteínas, el compromiso ventricular no depende del estado fibrinolíticos de la circulación sistémica, sino de la actividad en el líquido cefalorraquídeo (LCR), a menudo menos efectivo e incompleto.

Presentar la experiencia obtenida a partir del caso clínico posterior al uso de alteplasa intraventricular en un paciente con diagnóstico de mal formación arteriovenosa (MAV) complicada con hemorragia intraventricular cerebral (HIVCE) e hidrocefalia.

Palabras claves: MAV (Mal formación arterio venosa), DVE (derivación ventricular externa), (HIVCE) Hemorragia intraventricular cerebral, PIC (presión intracraneal), PPC (presión de perfusión cerebral)

\section{Caso clínico:}

Se trata de paciente de 19 años de edad sin app, referido a casa de salud particular presentando cuadro clínico de una hora de evolución caracterizado por cefalea Holo craneal, 4 vómitos, episodio convulsivo durante 2 a 3 minutos y posterior Glasgow de 6/15, procediéndose con entubación endotraqueal. En la unidad de tercer nivel se realiza Tac simple cerebral que devela hemorragia intracraneal Fisher 4.

Gráfico 1 Tomografía: corte tipo Fleming, se observa volcamiento ventricular Fisher 4, con pérdida de la diferenciación entre sustancia blanca y sustancia gris (edema cerebral).

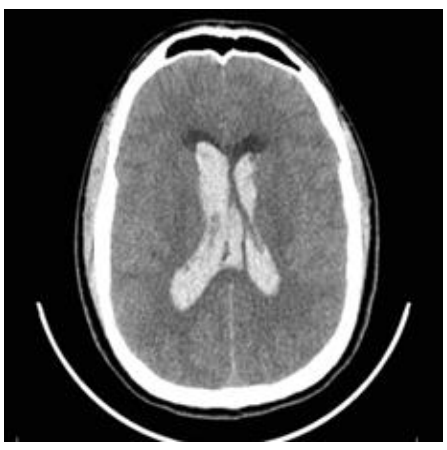


Elaborado por: Grupo de investigación

Gráfico 2 Tomografía: corte de Charcot, se observa imagen hiperdensa en área de vascularización de arteria cerebral anterior, con volcamiento ventricular hacia ventrículo lateral 1 y 2 más imagen hiperdensa en área de tercer ventrículo, con desplazamiento del supra tentorio al infra

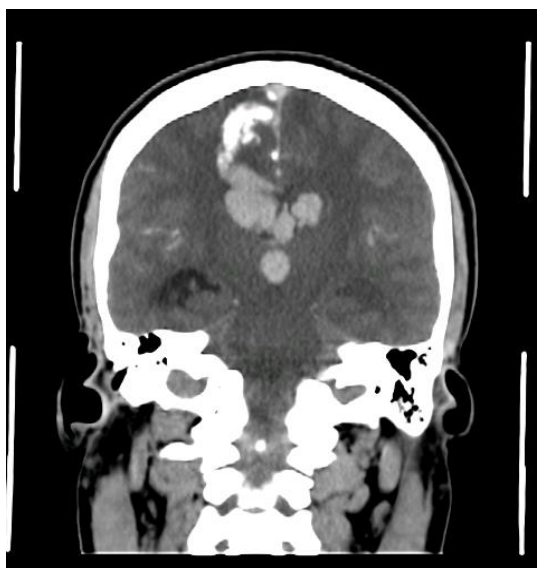

Elaborado por: Grupo de investigación

El mismo día se realiza arteriografía de vasos cerebrales y vertebrales con embolización de malformación de MAV con ónix, localizada en cerebral anterior.

Gráfico 3 Angiografía: imagen de hiperflujo en territorio vascular de arteria cerebral anterior derecha

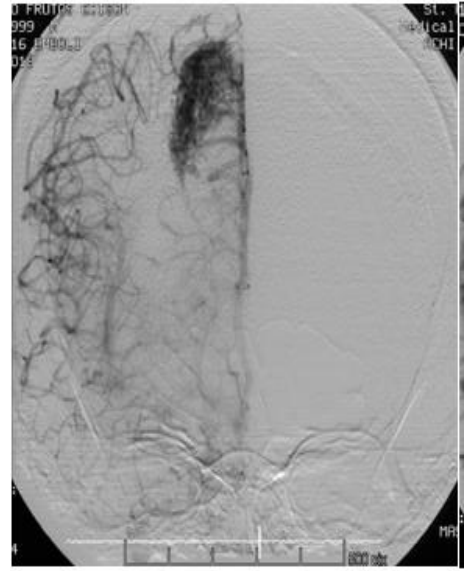

Elaborado por: Grupo de investigación

Gráfico 5 Angiografía: post embolización sin imagen de hiperflujo en arteria cerebral anterior. 


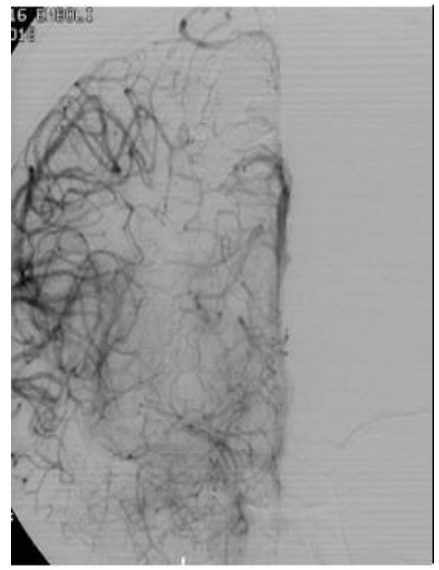

Elaborado por: Grupo de investigación

Gráfico N.6 Scout tomográfico de cráneo

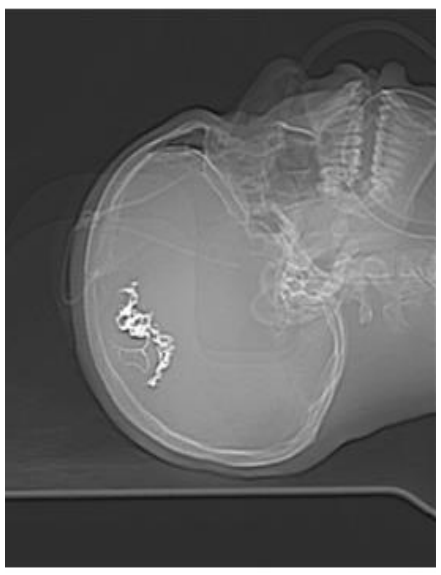

Elaborado por: Grupo de investigación

Luego se procede a realizar la derivación ventricular externa y lavados consecutivos de los ventrículos por 4 días con 2 ampollas de rt- PA. Evidenciándose en el paciente una evolución favorable tanto clínico como tomo gráficamente, luego de 20 días de internación en el área de cuidados intensivos y varias ventanas neurológicas se logra entubación, pasa a sala con anticonvulsivantes orales y a los 5 días se da el alta.

Las condiciones generales del paciente fueron excelentes, más persistió la disminución del tomo muscular en miembro inferior izquierdo.

Gráfico 7 Tomografía: se evidencia hemorragia intraventricular con dilatación entricular, muestra de derivación ventricular externa, en proceso resolutivo de hemorragia. 


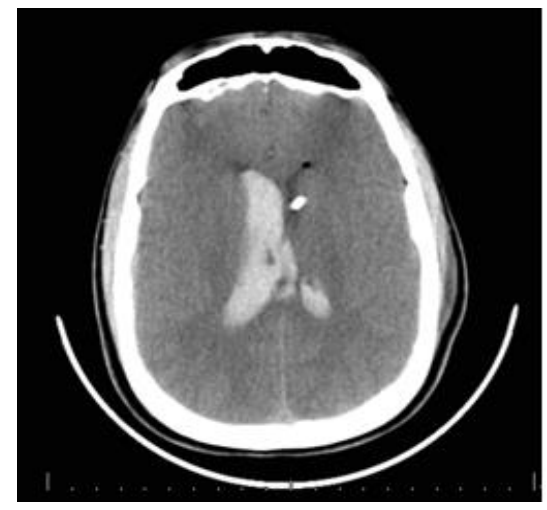

Elaborado por: Grupo de investigación

Gráfico N.8 Tomografía: corte a nivel del mesencéfalo, cisterna interpeduncular con imágenes hiperdensas en ventrículos laterales y tercer ventrículo, con sangrado de +-

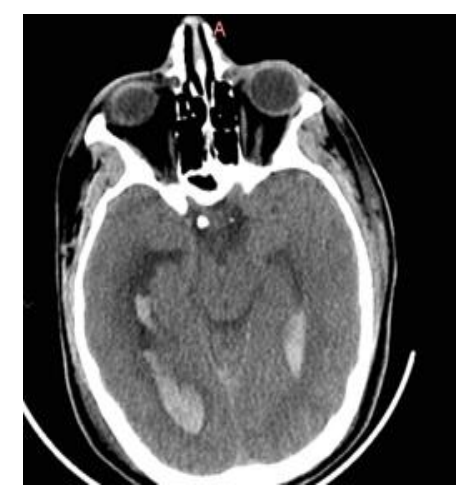

Elaborado por: Grupo de investigación

Gráfico N.9 Tomografía: donde se observan los núcleos caudados, se evidencian ventrículos libres, ligeramente agrandados, con áreas de poca diferenciación entre sustancia blanca y gris (edema cerebral ligero).

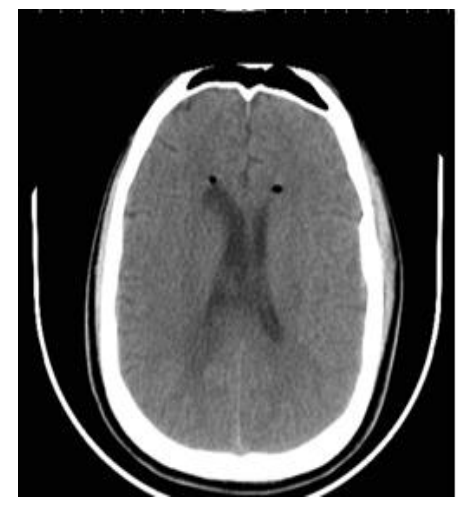

Elaborado por: Grupo de investigación 


\section{Metodología:}

Datos obtenidos a partir de análisis retrospectivo en función de la evolución clínicoquirúrgica y de neuroimagenes obtenidas a propósito de un caso de un paciente masculino de 19 años de edad sin otras comorbilidades con diagnóstico de hemorragia intraventricular cerebral secundaria a sangrado de MAV en quien se planteó el uso intraventricular de Alteplasa.

\section{Conclusiones}

- El uso de rt-PA (Alteplasa) intraventricular es una opción terapéutica cuando por objetivos se plantea el reducir la PIC, la PPC, y la probabilidad de desarrollar vasoespasmo por la presencia de sangre y con ello el aumento de la morbi-mortalidad.

\section{Referencias bibliográficas.}

Vereecken, K. K., T. Van Havenbergh, et al. (2006). "Treatment of intraventricular hemorrhage with intraventricular administration of recombinant tissue plasminogen activator a clinical study of 18 cases." Clin Neurol Neurosurg 108(5): 451-5

Bartek J Jr, Hansen-Schwartz J, Bergdal O, Degn J, Romner B, Welling KL, Fischer W. Alteplase (rtPA) treatment of intraventricular hematoma (IVH): safety of an efficient methodological approach for rapid clot removal. Acta Neurochir Suppl. 2011; 111:409-13. Doi: 10.1007/978-3-7091-0693-8_70. PubMed PMID: 21725792

Prat-Acín R, Galeano-Senabre I, Conde-García FJ, Febles-García P, González-Feria L. Tratamiento fibrinolíticos de la hemorragia intraventricular cerebral. Rev Neurol. 2001; 33(6):544-7.

Ñancupil C. Hemorragia Intraventricular y Trombolisis. Cuad Neurol [serie en línea]. 2001 $\begin{array}{lllll}\text { [citada } & 24 & \text { Sep } & 2010] ; 15 . & \text { Disponible }\end{array}$ http://escuela.med.puc.cl/publ/cuadernos/2001/14.html.

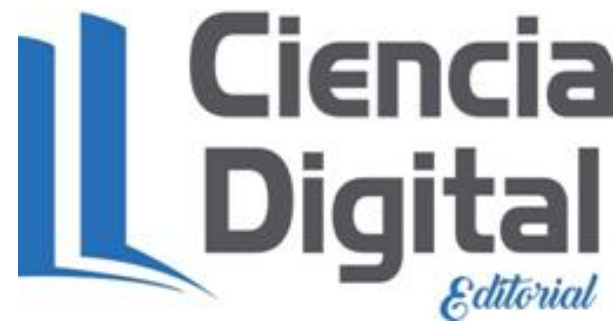




\section{Para citar el artículo indexado.}

Garcés K., Cuadrado M., Luzuriaga J. \& Martínez G. (2019). Uso de RT-PA alteplasa intraventricular en hemorragia intraventricular cerebral. Revista electrónica Ciencia Digital 3(1), 19-25. Recuperado desde:

http://cienciadigital.org/revistacienciadigital2/index.php/CienciaDigital/article/view/247/550

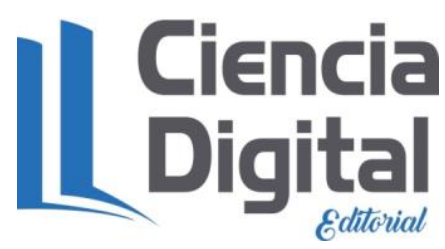

El artículo que se publica es de exclusiva responsabilidad de los autores y no necesariamente reflejan el pensamiento de la Revista Ciencia Digital.

El articulo queda en propiedad de la revista y, por tanto, su publicación parcial y/o total en otro medio tiene que ser autorizado por el director de la Revista Ciencia Digital.
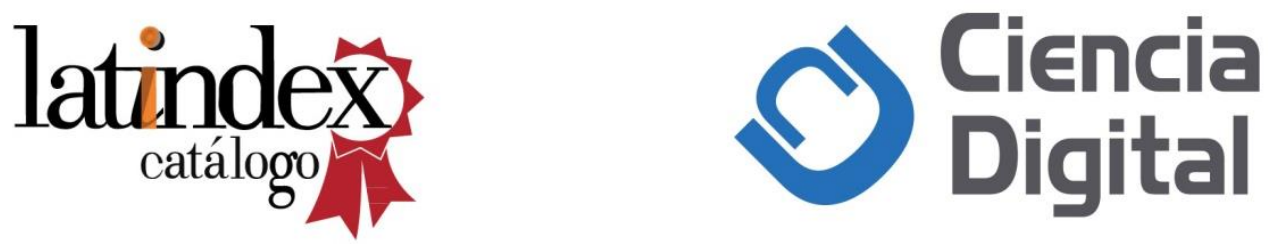